\title{
Optimasi Keakuratan Dimensi Produk Cetak 3D Printing berbahan Plastik PP Daur Ulang dengan Menggunakan Metode Taguchi
}

\author{
(Optimization of The Dimensional Accuracy of 3D Printing Products Made from \\ Recycled PP Plastic using The Taguchi Method) \\ Herda Agus Pamasaria ${ }^{a}$, Tri Hannanto Saputra ${ }^{b}$, Adhi Setya Hutama $^{c}$, Cahyo Budiantoro ${ }^{d}$ \\ ${ }_{a, b, c}$ Program Studi Teknologi Rekayasa Perancangan Manufaktur, Politeknik ATMI Surakarta \\ Jl. Adisucipto/ Jl. Mojo No.1 Surakarta \\ Phone: (0271) 271714466 \\ a herda.agus@atmi.ac.id, ${ }^{b}$ hannanto.saputra@atmi.ac.id, 'setya.hutama@atmi.ac.id \\ ${ }^{d}$ Program Studi Teknik Mesin, Fakultas Teknik, Universitas Muhammadiyah Yogyakarta Jalan \\ Lingkar Selatan Tamantirto, Kasihan, Bantul, DI Yogyakarta, Indonesia, 55183 \\ cahyo_budi@umy.ac.id,
}

\section{Abstrak}

Peningkatan jumlah sampah plastik di Indonesia disebabkan oleh meningkatnya penggunaan produk plastik. Menurut data, pada tahun 2018 sampah plastik akan diperkirakan 24.500 ton per hari. Daur ulang sampah plastik adalah salah satu cara untuk mengurangi jumlah sampah plastik di Indonesia. Pembuatan filamen 3D Printing berbahan plastik bekas daur ulang tidak hanya untuk mengurangi limbah sampah plastik, tetapi juga untuk memenuhi kebutuhan filamen untuk mesin 3D Printing tipe FDM (Fused Deposition Modeling). Dalam proses pembuatan produk, keakuratan dimensi menjadi faktor penting dalam mempengaruhi kualitas dan bentuk produk. Pada penelitian terkait keakuratan dimensi dilakukan dengan menggunakan metode Taguchi, dengan pengoptimalan parameter terukur seperti temperature printing, layer height and print speed. Penggunaan Signal to Noise Ratio (SNR) dengan tipe Smaller is Better untuk analisa hasil eksperimen yang memiliki tingkat perbedaan yang sedikit, dan untuk mengetahui parameter terukur yang berpengaruh dalam proses 3D Printing. Berdasarkan hasil analisa didapatkan parameter optimum untuk mencetak produk dengan dimensi $20 \times 20 \times 20 \mathrm{~mm}$, berbahan dasar material plastik daur ulang PP adalah untuk parameter printing temperature adalah $260{ }^{\circ} \mathrm{C}$, layer height $0,16 \mathrm{~mm}$ dan print speed $20 \mathrm{~mm} / \mathrm{s}$.

Kata kunci: Filamen Daur Ulang; 3D Printing; Metode Taguchi; SNR; Smaller is Better

\section{Abstract}

The increase in the amount of plastic waste in Indonesia is due to the increasing use of plastic products. According to data, in 2018 plastic waste will be estimated at 24,500 tons per day. Recycling plastic waste is one way to reduce the amount of plastic waste in Indonesia. Making 3D Printing filament from recycled used plastic material is one of the applications of how to reduce plastic waste, but also to fulfill the needs of filament for $3 D$ printing with FDM type printing. In the $3 D$ printing process with the FDM technique, dimensional accuracy is an important factor in influencing the quality and shape of the product. Research related to the accuracy of these dimensions is carried out using the Taguchi method, by optimizing measured parameters such as temperature printing, layer height and print speed. Smaller is Better type Signal to Noise Ratio $(S N R)$ is used to analyze the results of experiments that have the least difference, and to find out the measured parameters that affect the $3 D$ printing process Based on the analysis results, the optimum parameters for printing products with dimensions of $20 \times 20 \times 20 \mathrm{~mm}$, based on PP recycled plastic material are the printing temperature parameters $260 \mathrm{oC}$, layer height $0.16 \mathrm{~mm}$ and print speed $20 \mathrm{~mm} / \mathrm{s}$.

Keywords: Filamen Daur Ulang; 3D Printing; Metode Taguchi; SNR; Smaller is Better 


\section{Pendahuluan}

Penggunaan produk plastik yang tinggi mengakibatkan meningkatnya jumlah sampah plastik di Indonesia. Data dari Kementrian Lingkungan Hidup dan Kehutanan dalam Publikasi Statistik Lingkungan Hidup Indonesia (SLHI) tahun 2018 [1] menunjukkan bahwa timbunan sampah plastik di Indonesia pada tahun 2018 diperkirakan mencapai 24.500 ton per hari atau setara dengan 8,96 juta ton per tahun. Kondisi ini sangat berbahaya, karena sampah plastik butuh ratusan tahun untuk terurai ke lingkungan. Pembuatan filamen 3D printing dari bahan recycle plastik bekas merupakan salah satu langkah yang cukup tepat dalam mengatasi masalah sampah plastik tersebut, hal ini juga sejalan dengan semakin meluasnya penggunaan mesin 3D printing terutama dengan metode Fused Deposition Modelling (FDM). Dengan pembuatan filamen 3D printing dari bahan daur ulang plastik bekas, maka akan mengurangi sampah plastik yang ada, di samping itu juga dapat memenuhi besarnya kebutuhan filamen untuk proses cetak 3D printing dengan menggunakan teknik FDM.

Penggunaan filamen dari bahan plastik daur ulang perlu mempertimbangkan kualitas produk hasil cetak yang dihasilkan [2] Pada proses pengerjaan 3D printing dengan teknik FDM, akurasi dimensi menjadi faktor penting yang mempengaruhi kualitas [3]. Faktor tersebut menjadi pertimbangan utama dalam mencetak komponen. Dari pertimbangan tersebut, perlu dilakukan penelitian untuk melihat kualitas produk hasil cetak $3 D$ printing menggunakan filamen dari bahan daur ulang plastik. Penelitian ini bertujuan untuk mendapatkan data parameter proses yang paling optimal agar menghasilkan produk cetak $3 D$ printing berkualitas dengan menggunakan filamen dari daur ulang plastik bekas. Parameter $3 D$ printing yang mempengaruhi akurasi dimensi adalah layer thickness, build orientation, raster orientation, extrusion temperature, air gap, raster width dan print speed [4]. Pada penelitian ini, paramater-parameter dari 3D printing seperti temperature, layer height, dan printing speed dioptimasikan untuk mendapatkan produk produk 3D printing dengan akurasi dimensi (panjang lebar dan tebal) optimum.

\section{MetOde}

\subsection{Alat dan Bahan}

Penelitian ini menggunakan mesin 3D Printing Creality Ender 3 Pro (Gambar 2.1) untuk menghasilkan produk spesimen berdimensi $20 \times 20 \times 20 \mathrm{~mm}$. Desain spesimen menggunakan software Solid Work 2018. Software untuk mencetak spesimen menggunakan Slicer : Repetier Host - Cura versi 2.1.3

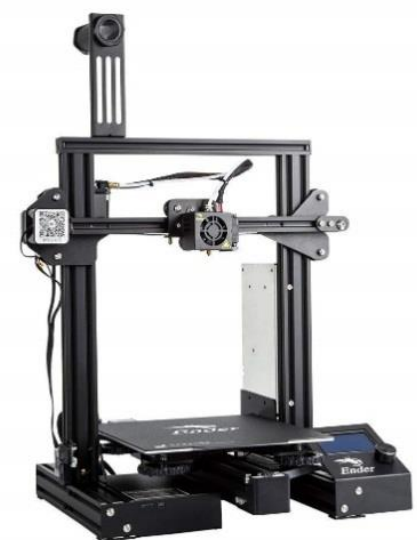

Gambar 2.1. Mesin 3D Printing Creality Ender 3 Pro 
Pengukuran dimensi spesimen menggunakan dial caliper 0-150 mm merk Mitutoyo dengan ketelitian 0,02 mm, dan outside micrometer 0-25 mm merk Mitutoyo dengan ketelitian 0,01 mm (Gambar 2.2).

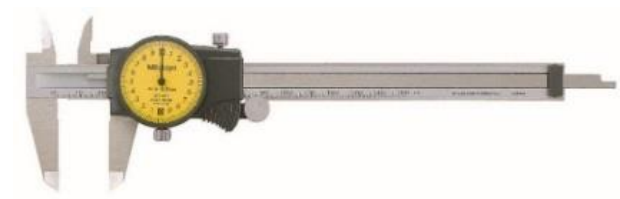

(a)

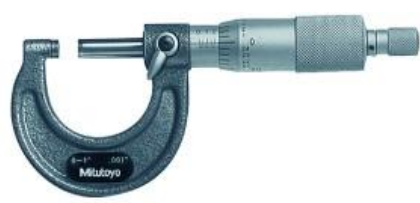

(b)

Gambar 2.2. (a) Dial Caliper (b) Outside Micrometer

Bahan untuk pembuatan spesimen penelitian adalah adalah filamen dari material daur ulang plastik bekas. Filamen didapatkan dari produsen filamen berbahan daur ulang plastik bekas. Dalam penelitian ini produk daur ulang plastik yang digunakan berjenis PP (Gambar 2.3), dan material data sheet dari filamen daur ulang plastik PP dapat dilihat pada Tabel 2.1.

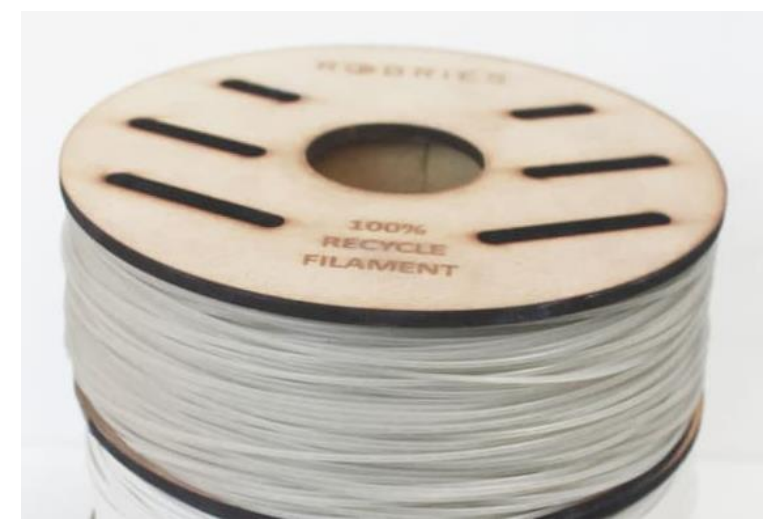

Gambar 2.3. Filamen Daur Ulang Plastik PP

Tabel 2.1. Material Data Sheet Filamen Daur Ulang Plastik Dengan Jenis PP

\begin{tabular}{cc} 
Properti & Keterangan \\
\hline Diameter & $1,75 \mathrm{~mm}$ \\
Specific Gravity & $0,9 \mathrm{gr} / \mathrm{cm}^{3}$ \\
Tensile Strength & $26 \mathrm{MPa}$ \\
Impact Strength & $0,05 \mathrm{~kJ} / \mathrm{m}$ \\
Surface & Matte \\
Transparancy & Opaque \\
Processibility & Good
\end{tabular}




\subsection{Metode}

Proses penelitian diawali dengan studi pustaka, dilanjutkan dengan persiapan peralatan dan bahan. Pembuatan spesimen digunakan filamen daur ulang plastik PP, dengan variasi parameter disesuaikan Metode Taguchi. Gambar 3 dimensi dengan ukuran 20x20x20 mm sesuai dengan gambar 2.4. dibuat menggunakan software Solid Work 2018, kemudian gambar di simpan dalam format STL. Contoh gambar 3 dimensi dapat dilihat pada Gambar 2.5. Pengukuran dimensi spesimen meliputi panjang lebar dan tebal spesimen. Pada tahap analisa, Signal to Noise Ratio (SNR) dengan pilihan Smaller is Better digunakan untuk menganalisa tingkat perbedaan yang paling minimum. Diagram Alir penelitian dilihat pada gambar 2.6.
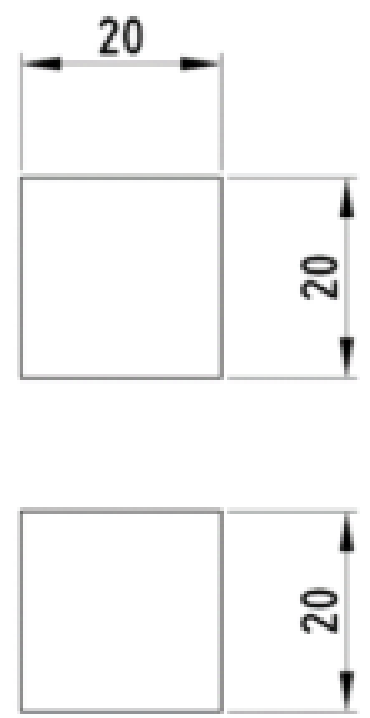

Gambar 2.4. Ukuran Produk Hasil Printing

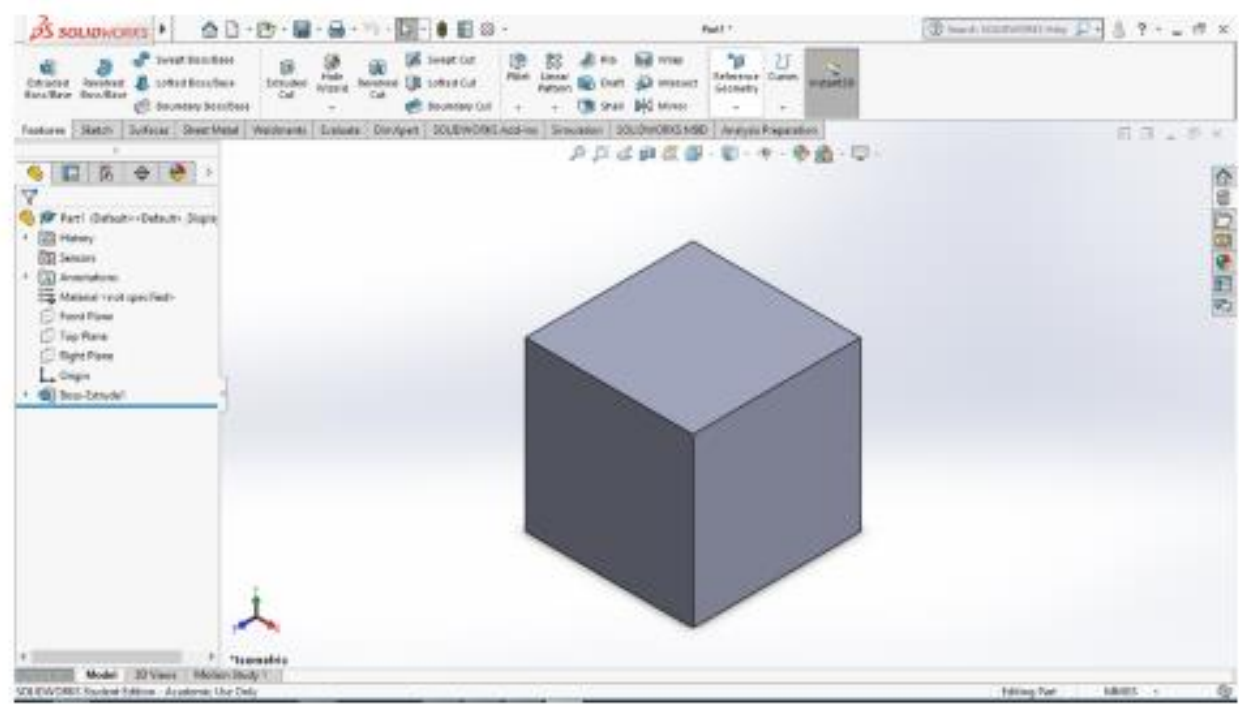

Gambar 2.5. Gambar 3D Solid work 2018 


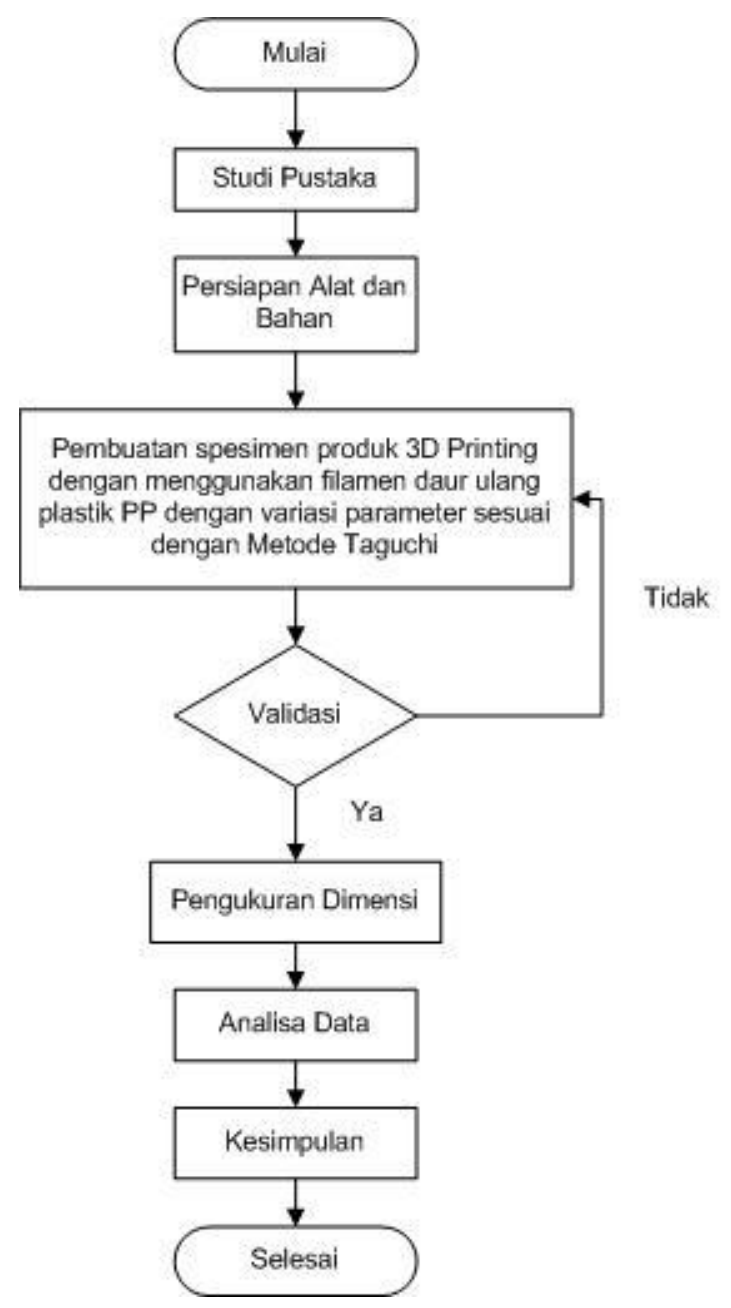

Gambar 2.6 . Alur Penelitian Optimasi Parameter FDM 3D Printing

Salah satu metode optimasi yang sering dipakai adalah metode Taguchi. Metode ini diperkenalkan oleh Dr. Genichi Taguchi pada tahun 1940. Pendekatan Taguchi ini berbeda dengan pendekatan lainnya, yakni lebih menekankan pada aspek kualitas. Selain itu Taguchi menggunakan perancangan eksperimen sebagai alat untuk membuat produk lebih kokoh (robust), yakni produk menjadi tidak terpengaruh terhadap faktor noise. Perancangan eksperimen ini digunakan sebagai alat untuk mengurangi variasi terhadap karakteristik kualitas produk dan proses. Penggunaan metode Taguchi dalam desain eksperimen berdasarkan pada Orthogonal Array $(O A)$ untuk mendapatkan jumlah maksimum informasi dengan percobaan minimal, selain itu juga dapat menganalisis data eksperimen berdasarkan Signal to Noise Ratio (SNR) [5]. Orthogonal array $(O A)$ adalah suatu matriks yang elemen - elemennya tersusun atas baris dan kolom. Baris merupakan kombinasi level dari faktor dalam eksperimen. Setiap kolom merupakan faktor yang dapat diubah dalam eksperimen. Filosofi Taguchi terdiri dari tiga konsep, yaitu kualitas harus dirancang ke dalam produk dan bukan sekedar memeriksanya, kualitas terbaik dicapai dengan meminimumkan deviasi dari target, produk harus dirancang agar kokoh (robust) terhadap faktor lingkungan yang tidak dapat dikontrol, biaya kualitas harus diukur sebagai fungsi deviasi dari standar tertentu dan kerugian harus diukur pada seluruh sistem [6].

Orthogonal Array digunakan untuk menganalisis data eksperimen dan digunakan untuk merancang eksperimen yang efisien sehingga dapat menentukan jumlah eksperimen minimal yang dapat memberikan informasi sebanyak mungkin semua faktor yang 
mempengaruhi parameter [7]. Pemilihan jenis Orthogonal Array yang digunakan pada eksperimen tergantung pada jumlah derajat bebas. Penentuan derajat bebas bermaksud untuk melihat berapa minimum banyaknya percobaan yang dilakukan. [8] Perumusannya dapat dilihat pada persamaan 2.1.

$$
\begin{aligned}
& \text { Derajat bebas }=\sum_{k=1}^{n}\left(l_{k}-1\right) \\
& \text { dengan, } \mathrm{k}=1,2, \ldots, \mathrm{n}
\end{aligned}
$$

Metode Taguchi memiliki keuntungan dalam hal uji coba, karena parameter terukur telah dimodifikasi menjadi susunan Orthogonal Array, dan mentransformasi data yang diperoleh dalam bentuk Signal to Noise Ratio $(S N R)$. SNR mengakomodasi berbagai jenis optimasi yang diperlukan oleh peneliti dan diberikan 3 pilihan, yaitu smaller is better (2.2), nominal the better (2.3), dan larger the better (2.4) [9].

$$
\begin{aligned}
& \text { Smaller is better } \\
& \frac{S}{N R}=-10 \log _{10}\left[\frac{1}{n} \sum_{i=1}^{n} y_{i}{ }^{2}\right]
\end{aligned}
$$

Larger the Better

$$
\frac{S}{N R}=-10 \log _{10}\left[\frac{1}{n} \sum_{i=1}^{n} \frac{1}{y_{i}{ }^{2}}\right]
$$

Nominal the Better

$$
\frac{S}{N R}=10 \log _{10} \frac{\mu^{2}}{\sigma^{2}}
$$

\section{Hasil dan Pembahasan}

\subsection{Penentuan Parameter Terukur dan Orthogonal Array}

Terdapat 3 parameter terukur yang diteliti untuk mendapatkan bentuk spesimen yang optimal, yaitu printing temperature, layer height, dan printing speed. Setiap parameter ditentukan 3 level (minimum, middle, dan maksimum), dan penentuan level didasarkan rekomendasi dari karakter material plastik daur ulang PP (Tabel 3.1).

Tabel 3.1. Parameter terukur dan Level

\begin{tabular}{lcccc}
\multicolumn{1}{c}{ Parameter terukur } & $\begin{array}{c}\text { Rekomendasi } \\
\text { PP }\end{array}$ & \multicolumn{3}{c}{ Level } \\
\hline Printing temperature $\left({ }^{\circ} \mathbf{C}\right)$ & $230-260$ & 230 & 245 & 260 \\
\hline Layer height $(\mathbf{m m})$ & $0,12-0,20$ & 0,12 & 0,16 & 0,20 \\
\hline Printing speed $(\mathbf{m m} / \mathbf{s})$ & $20-50$ & 20 & 35 & 50 \\
\hline
\end{tabular}

Banyaknya percobaan yang dipilih dalam Orthogonal Array harus lebih besar atau setidaknya sama dengan banyaknya percobaan yang diperoleh dari hasil perhitungan derajat bebas. Dari perhitungan didapatkan derajat kebebasan (DOF) sebesar 6, maka jumlah eksperimen yang harus diambil minimal bejumlah 6 , sehingga penelitian ini menggunakan Orthogonal Array L9 yang memiliki jumlah ekperiman berjumlah 9.

Data pada 3.1 diolah dengan Orthogonal Array L9 sehingga dihasilkan variasi parameter yang digunakan dalam penelitian ini. Untuk material PP ditunjukkan pada Tabel 3.2 
Tabel 3.2. Orthogonal Array L9

\begin{tabular}{ccccccc}
\hline No & \multicolumn{3}{c}{ Parameter Terukur } & \multicolumn{3}{c}{ Parameter Respon } \\
\hline $\begin{array}{c}\text { Printing } \\
\text { Temperature } \\
\text { ( C) }\end{array}$ & $\begin{array}{c}\text { Layer } \\
\text { Height } \\
(\mathbf{m m})\end{array}$ & $\begin{array}{c}\text { Print } \\
\text { Speed } \\
(\mathbf{m m} / \mathbf{s})\end{array}$ & Panjang & Lebar & Tebal \\
\hline $\mathbf{1}$ & 230 & 0,12 & 20 & $\mathrm{X} 1$ & $\mathrm{Y} 1$ & $\mathrm{Z} 1$ \\
\hline $\mathbf{2}$ & 230 & 0,16 & 35 & $\mathrm{X} 2$ & $\mathrm{Y} 2$ & $\mathrm{Z} 2$ \\
\hline $\mathbf{3}$ & 230 & 0,20 & 50 & $\mathrm{X3}$ & $\mathrm{Y3}$ & $\mathrm{Z3}$ \\
\hline $\mathbf{4}$ & 245 & 0,12 & 35 & $\mathrm{X} 4$ & $\mathrm{Y} 4$ & $\mathrm{Z} 4$ \\
\hline $\mathbf{5}$ & 245 & 0,16 & 50 & $\mathrm{X} 5$ & $\mathrm{Y} 5$ & $\mathrm{Z}$ \\
\hline $\mathbf{6}$ & 245 & 0,20 & 20 & $\mathrm{X} 6$ & $\mathrm{Y} 6$ & $\mathrm{Z}$ \\
\hline $\mathbf{7}$ & 260 & 0,12 & 50 & $\mathrm{X} 7$ & $\mathrm{Y} 7$ & $\mathrm{Z}$ \\
\hline $\mathbf{8}$ & 260 & 0,16 & 20 & $\mathrm{X} 8$ & $\mathrm{Y} 8$ & $\mathrm{Z} 8$ \\
\hline $\mathbf{9}$ & 260 & 0,20 & 35 & $\mathrm{X} 9$ & $\mathrm{Y} 9$ & $\mathrm{Z} 9$ \\
\hline
\end{tabular}

Setiap variasi parameter di cetak sebanyak 3 spesimen, sehingga setiap jenis filamen dicetak sebanyak 27 spesimen. Semua spesimen diukur dengan alat ukur yang telah disediakan meliputi ukuran panjang lebar dan tebal.

\subsection{Perhitungan Signal to Noise Ratio (SNR)}

Pada Tabel 3.3 merupakan nilai SNR dari pengolahan data Orthogonal Array dengan sembilan kali percobaan, dan 3 kali repetisi. Jenis SNR yang digunakan adalah smaller is better. Smaller is better merupakan karakteristik terukur non negative dengan nilai ideal nol. Contoh yang termasuk kategori ini antara lain penggunaan mesin, penyimpangan, waktu proses, pemborosan panas, persentase kontaminasi, kebisingan, waktu respon, pemborosan energi, hambatan, produk gagal, dan kerusakan Produk [10].

Rumus untuk SNR dengan karakteristik Smaller is Better adalah sebagai berikut:

$$
\frac{S}{N R}=-10 \log _{10}\left[\frac{1}{n} \sum_{i=1}^{n} y_{i}^{2}\right]
$$

Dimana :

$y_{j k}^{i}=$ nilai respon ke-j pada percobaan

Tabel 3.3. Hasil Analisa Signal to Noise Ratio Smaller is Better

\begin{tabular}{ccccccc} 
& \multicolumn{2}{c}{ Parameter Terukur } & \multicolumn{3}{c}{ Nilai } \\
No & $\begin{array}{c}\text { Printing } \\
\text { Temperature }\end{array}$ & $\begin{array}{c}\text { Layer } \\
\text { Height }\end{array}$ & $\begin{array}{c}\text { Print } \\
\text { Speed }\end{array}$ & $\begin{array}{c}\text { SNR Deviasi } \\
\text { Panjang }\end{array}$ & $\begin{array}{c}\text { SNR } \\
\text { Deviasi } \\
\text { Lebar }\end{array}$ & $\begin{array}{c}\text { SNR } \\
\text { Deviasi } \\
\text { Tebal }\end{array}$ \\
\hline $\mathbf{1}$ & 230 & 0,12 & 20 & 12,76 & 11,61 & 14,81 \\
\hline $\mathbf{2}$ & 230 & 0,16 & 35 & 10,82 & 9,24 & 16,10 \\
\hline $\mathbf{3}$ & 230 & 0,2 & 50 & 10,11 & 8,53 & 11,05 \\
\hline $\mathbf{4}$ & 245 & 0,12 & 35 & 11,14 & 9,72 & 13,13 \\
\hline $\mathbf{5}$ & 245 & 0,16 & 50 & 10,01 & 8,46 & 15,69 \\
\hline $\mathbf{6}$ & 245 & 0,2 & 20 & 13,27 & 11,18 & 10,84 \\
\hline $\mathbf{7}$ & 260 & 0,12 & 50 & 11,15 & 8,92 & 13,53 \\
\hline $\mathbf{8}$ & 260 & 0,16 & 20 & 13,85 & 11,72 & 17,60 \\
\hline $\mathbf{9}$ & 260 & 0,2 & 35 & 12,52 & 10,49 & 11,16 \\
\hline
\end{tabular}

Ciri khas Signal to Noise Ratio dengan jenis Smaller is Better adalah memiliki nilai ratarata tertinggi untuk setiap analisis dari setiap percobaan. Pada Tabel 3.3. menunjukan nilai 
SNR tertinggi adalah pada percobaan ke-8, yaitu parameter respon panjang dengan nilai deviasi adalah 13,85; lebar 11,72 dan tebal 17,6. Pada analisa menggunakan software minitab 15 juga dijelaskan bahwa parameter yang paling berpengaruh adalah print speed, dengan nilai delta yang paling besar, 1,53 (Gambar 3.1).

\begin{tabular}{|c|c|c|c|}
\hline \multicolumn{2}{|c|}{$\begin{array}{l}\text { Response Table for } \\
\text { Smaller is better }\end{array}$} & Signal & o Noise \\
\hline & Printing & Layer & Print \\
\hline Level & Temperature & Height & Speed \\
\hline 1 & $-21,40$ & $-21,54$ & $-22,37$ \\
\hline 2 & $-21,35$ & $-22,20$ & $-21,39$ \\
\hline 3 & $-21,85$ & $-20,85$ & $-20,83$ \\
\hline Delta & 0,50 & 1,35 & 1,53 \\
\hline Rank & 3 & 2 & 1 \\
\hline
\end{tabular}

Gambar 3.1. Parameter Terukur yang Paling Berpengaruh

\section{KesimpuLAN}

Berdasarkan hasil analisa dengan menggunaan metode Taguchi dengan pemilihan SNR adalah smaller is better, menunjukan bahwa parameter printing temperature $260{ }^{\circ} \mathrm{C}$, layer height $0,16 \mathrm{~mm}$ dan print speed $20 \mathrm{~mm} / \mathrm{s}$ merupakan parameter optimum untuk mesin $3 \mathrm{D}$ printing dengan jenis FDM dengan material plastik daur ulang PP, dalam mencetak produk dengan dimensi 20x20x20 mm.

Untuk penelitian kedepannya, diharapkan terdapat penelitian untuk menguji optimasi parameter yang digunakan mesin 3D printing dengan jenis FDM dengan membandingkan beberapa tipe material dari plastik daur ulang, sehingga mendapatkan parameter yang lebih optimum lagi dan dapat menambah literasi penelitian terkait pemanfaatan plastik daur ulang.

\section{Daftar Pustaka}

[1] Arup, D, Nita, Y, A Systematic Survey of FDM Process Parameter Optimization and Their Influence on Part Characteristics. Journal of Manufacturing and Materials Processing, 2019, vol 3, no. 3

[2] Pamasaria, H.A., Herianto, Saputra, T.H., Pengaruh Parameter Proses 3D Printing Tipe FDM (Fused Deposition Modelling) Terhadap Kualitas Hasil Produk, Seminar Nasional IENACO, pp. 201-207. Universitas Muhammadiyah Surakarta. Jawa Tengah. 2019

[3] Saputra, T.H., Herianto, Pamasaria, H.A, Analisa Pengaruh Pemilihan Komponen Terhadap Ketelitian Dimensi dan Kualitas Permukaan Produk Pada Mesin 3D Printing Jenis FDM (Fused Deposition Modelling), Seminar Nasional IENACO, pp. 208-214. Universitas Muhammadiyah Surakarta. Jawa Tengah. 2019

[4] Arup, D, Nita, Y, A Systematic Survey of FDM Process Parameter Optimization and Their Influence on Part Characteristics. Journal of Manufacturing and Materials Processing, 2019, vol 3, no. 3.

[5] Taguchi, G., Taguchi on robust technology development: bringing quality engineering upstream, ASME Press, New York. 1993

[6] Djami, R.J., Sunaryo, S., Metode PCR-TOPSIS Untuk Optimasi Taguchi Multirespon, Statistika, 2014, vol. 2, no. 1, pp. 46-55.

[7] Pamasaria, H,A. Pengaruh Parameter 3D Printing Tipe FDM (Fused Deposition Modelling) Terhadap Kualitas Hasil Produk menggunakan Filament Berbahan Daur Ulang Plastik. Thesis. Yogyakarta : Universitas Gadjah Mada

[8] Sunengsih, N., Winarni, S., dan Amzainaa, T.G., Kajian Terhadap Metode TaguchiTOPSIS Pada Optimasi Multirespon, Seminar Statistika FMIPA UNPAD, pp. 496-507. Universitas Padjajaran. Jawa Barat. 2017

[9] Nugroho, T.A., Hutama, A.S., Metode Taguchi - PCR TOPSIS untuk Optimasi Parameter Mesin Laser Grafir, POLITEKNOSAINS, 2019, vol. XVIII, no. 1, pp. 6-11.

[10] Ross, P.J., Taguchi Techniques for Quality Engineering 2nd edition. McGraw-Hill Book Company, New York. 1996 
